\title{
Study on Strategy of Human Resources Development in Western China
}

\author{
Chun Zheng \\ Xi’an International University, Xi’an, Shaanxi, 710077
}

Keywords: human resource; western region; development strategy

\begin{abstract}
In any period of any activity, human resources as an important resource, play a key role. If there is no human resources, other types of social resources are not fully and coordinated to play its unique function. With the rapid development of modern society and the continuous progress of science and technology, the role and status of human resources are more and more prominent in the social development. In the era of knowledge economy, people attach great importance to human resources development in the world, and China's western region is no exception. As an important resource for the development of modern society, the development level and development effect of human resources have determined the development of economy and society in the west of China in some cases. It is not only an effective guarantee to promote the development of the western region, but also a solid foundation for the realization of socialist modernization in the western region of our country, to develop human resources in western region fully, reasonably and efficiently. Therefore, it is one of the main ways to solve the problem of human resources development in the west of China to further expand the thinking of human resources development in the ethnic minority areas of our country.
\end{abstract}

\section{Introduction}

China is a unified multi-ethnic country, the country is distributed throughout the 55 ethnic minorities, the total population of more than 100 million. The western region is one of the main areas of ethnic minorities in China. The complex natural geography environment and social history and culture make the human resources of the western region show its unique characteristics. China's western region the number of human resources, the overall quality is low, its development is far from being able to meet the needs of socialist modernization and the western development strategy, so how can the existing human resources to rational development And use, is a huge challenge we face. The comprehensive implementation of the western development strategy also requires us to attach great importance to human resource development in the western region. However, the experience of history and reality proves that human resource is the key factor and important impetus to promote the economic and social development and progress of mankind. Human resources, as a kind of "living" and special resources, cooperate with and interact with other kinds of resources in many social resources, such as natural resources, capital resources, human resources, information resources and so on, to the progress of modern society and economy The development has played a vital role. At the same time, human resources is also a variety of other types of material resources into a decisive factor in social wealth. The so-called "social wealth", mainly refers to people's material and spiritual life has a certain value of the product in general. However, natural resources, information resources, etc. do not directly have this usability, so people need to pay a certain amount of labor to control and adjust the material transformation process, and to maximize the transformation of these material resources into social wealth. Thus, human resources in the creation of social wealth, the development process of production occupies an extremely important position.

\section{The Importance of Human Resource Development in Western Region}

Due to the social history and the physical geographical environment and other factors, the overall level of social development is not high, with the eastern region showing a certain gap. Moreover, the western region has encountered many difficulties in the process of human resource development, 
such as the serious shortage of technical personnel in agriculture and animal husbandry in many areas and the lack of basic education teachers. These difficulties have seriously hindered the development of local production and the improvement of people's quality of life. Therefore, in the course of carrying out the western development strategy, we must pay special attention to human resources development in the western region. Only in this way can the western region realize the comprehensive and healthy development of the economy and society. At the same time, it is also the people of all ethnic groups to achieve national equality, National unity and the common prosperity of all ethnic groups. At present, western China's industrial structure is not reasonable, the primary industry still accounts for a large proportion, the majority of employees are stranded in the primary industry. However, in a certain period of time, if the total labor force of the same, the practitioners is too concentrated in the primary industry, to some extent bound to excessive occupation of the secondary industry, tertiary industry, employment, and thus severely limited The second industry, the tertiary industry for further development. It can be said that the development of the secondary and tertiary industries, especially the tertiary industry, is an important indicator of the overall level of economic development of a region. However, the development of industry and service industry requires a large number of professional and technical personnel, while the western region of the talent is extremely scarce, the existing human resources, both in terms of quantity and quality are difficult to meet at this stage of the secondary and tertiary industries Development needs, which has become the industrial structure optimization and upgrading of the huge resistance. Therefore, vigorously cultivating talents is an important driving force for the adjustment of industrial structure in the western region.

\section{The Environmental Factors of Human Resource Development in the West of China}

In November 1999, the central economic work conference made an important decision, namely the implementation of the western development strategy. However, the western development strategy of the proposed development of human resources in the western region has a very important significance. The implementation of the strategy of rejuvenating the nation through science and education and the strategy of strengthening the country through the use of talents has promoted the development of the productive forces and technological progress in the western region, and provided technical and talent support for the economic restructuring and industrial restructuring. On the other hand, the development of the educational undertakings in the western region To the opportunity to promote the educational philosophy of the change, teaching equipment, the upgrading of the level of teachers and all levels of education in the coordinated development of talent training and the introduction of laid a solid foundation. Therefore, the strategy of rejuvenating the country through science and education and the strategy of strengthening the nation by talents also provide a favorable environment for the development of human resources in the western region.

Therefore, the study of human resources development and sustainable economic development in the western region must not cut off the link between history and human resources development in the western region of China. Therefore, the study of human resources development in the western region and the sustainable development of the economy must not cut off the link between history and the history of human resources development in western China. . The slow development of human resources in the western region, the overall economic situation is still poor and backward, this is a profound social and historical reasons. The old social form, long-term cultural traditions and ideological ideology dominated the specific behavior of workers, to the local economic and social development plays a more tenacious resistance, which led to the country to a small number of western regions Capital and scientific and technological personnel in various fields are difficult to play its due effect.

The backwardness of the concept of some leaders is one of the main factors that hinder the development of human resources in the western region. On the one hand, under the influence of utilitarianism, many leading cadres in the western region have only one-sided pursuit of political achievements, image projects, and short-term economic benefits, while ignoring the development of 
national education can bring long-term social benefits, The development of education in the top priority, resulting in a lot of waste of resources and the slow development of national education; the other hand, the lack of understanding of the relationship between education and economic development, many leading cadres that the western region of the backward level of productivity, Low level of development, the development of education is even more distant things, so do not want to take proactive measures to respond to the development of education in the western region to seek a way out, but negatively ", rely on, to" seriously affect the western Sustainable Development of Regional Human Resources.

The development of productive forces in the western region is generally backward, and the industrial structure is single. For a long time, it has been based on the extensive production methods of agriculture and animal husbandry. The economic and social development is very slow. Therefore, the people of the scientific and cultural knowledge, production technology, little demand. In addition, the western region is relatively low level of education, backward educational philosophy, old textbooks, aging teaching facilities and weak faculty and other factors can not meet the needs of modern social development, and that this backward education can not make people will The cultural knowledge and production skills immediately translated into economic benefits.

\section{Main Modes and Countermeasures of Human Resource Development in the West of China}

Human resources development model is complex and diverse, of which, education and training is the most critical way and means. It is a positive exploration to combine the school education and vocational training as the core model of human resources development to realize the system development and standard development of human resources. On the one hand, school education is the most important part of human resource development in the western region of China, and basic education is the key stage in school education. The main goal of school education is to cultivate the basic scientific and cultural quality of human resources, ideological and moral qualities, the main object of training is not employed in school students. On the other hand, vocational training is also an important part of human resource development in the western region. In the process of developing vocational training, the western region should adhere to the principle of combining central support with local self-reliance to form a multi-level and systematic vocational training system, and focus on vocational training institutions at the county and township (town) levels. Construction, at the same time, the need to local economic development of the actual situation, especially the local competitive industries, the characteristics of industry and vocational training closely integrated to the full realization of the western region the development of vocational training is expected to effect. Vocational training as an important complement to the development of human resources, its goal is to cultivate the basic practical ability of workers, the main object of training is the community has been employed or participate in pre-job study personnel.

Therefore, under the existing conditions, all levels of government departments and relevant leaders in the western region must establish the new concept that "human resources are the first resource" and fully realize that human resources are the greatest wealth and the most valuable resource in many social resources Of renewable resources in the development of social productive forces and building a harmonious society in the important role.

It is generally believed that accelerating the construction of urban and rural infrastructure in the western region should be carried out in the following aspects: on the one hand, the overall planning of the western region should be strengthened, and scientific planning and system management should be taken to promote the transportation, public utilities, information, water conservancy and electricity. Construction; on the other hand, in the market economy environment, the construction of infrastructure in the western region to get rid of simply relying on national investment, bank loans, traditional ideas, fully and flexibly highlight the role of the market, thus diversified investment path. In addition, it is necessary to break the administrative monopoly practiced under the existing planned economy system, insist on the direction of marketization and modernization, and realize the enterprise and group transformation of infrastructure management and management in the western region. 
The construction and development of the human resources market in the western region is directly related to whether the human resources can achieve reasonable flow and effective allocation. Therefore, to promote the construction of human resources market need to start from the following points: First, to break the region, between industries and sectors between the various barriers, give full play to the role of market mechanisms to promote human resources in different regions, industries, The free flow between departments, the rational allocation; Secondly, to establish a more comprehensive, unified human resources market management system and laws and regulations, and strengthen human resources supply and demand both legal concepts to protect the legitimate interests of both business and workers; Third, according to the regional, industry development needs, the human resources market construction of scientific and rational planning and layout, and actively play all levels of government departments on the local human resources market regulation and control; Finally, increase the Social security, vocational skills training and other aspects of investment, and establish a human resources market and supporting the construction of quality service system, and continuously improve the quality of human resources market and work efficiency, so that workers fully reflect its own value and see Its own good development prospects, so as to better into the western region of economic and social development and construction.

\section{Conclusion}

In recent years, the research on human resources development in the western region has been paid more and more attention by the academic circles. Because human resource development in the western region is not the same as the human resources development environment, present situation and problems in other regions, especially in the eastern developed regions, the proposed development model and the solution to the problem is not the same. Based on the guidance of the tutors and the help of the tutors, this paper takes the western region as the research area, from the realistic environment as a whole, and makes a comprehensive study on the human resource development in the western region. I hope that through this topic, the relevant departments of the western region to increase human resource development and personnel training and attention, and can use a variety of models and specific measures to effectively improve the overall quality of local human resources, and then in the whole society The formation of a good atmosphere of respect for talent.

\section{References}

[1] Zhang Han. Some Thoughts on the Construction of Talent Market in Ethnic Regions [J]. Yanbian University Journal, 2011 (01)

[2] Yang Minghong. A new round of the western development of the strategic objectives: to promote the western minority areas to share more "Development Bonus" [J]. Ethno-National Studies, 2011 (01)

[3] Wang Jian, Zhang Hai. The Research on the Present Situation and Development of Human Resources in the Minority Areas of China [J]. Journal of Northwest Normal University, 2009 (06)

[4] Li Guiying. Research on Economic Development Status and Causes of the Western Minority Areas [J]. Journal of Jilin Province Economic Management Cadre College (Social Science Edition); 2008-02

[5] Cao Ping, Liang Jijiang. Study on the Problems and Countermeasures in the Development of Elementary Education in Ethnic Areas [J]. Ethnic Education Research, 2009 (04) 